\title{
THE ANALYSIS OF THERMAL EFFICIENCY OF CCGT WITH BACK- PRESSURE VIA THE METHODS OF SMALL-DEFLECTION
}

\author{
Artem A. Uvarov ${ }^{1}$ and Aleksandra M. Antonova ${ }^{1, *}$ \\ ${ }^{1}$ Tomsk Polytechnic University, 634050, Tomsk, Russia
}

\begin{abstract}
Presents the results of studying the influence of efficiency gas turbine and steam section of CCGT on the thermal efficiency of combinedcycle plant with back-pressure based on a powerful high-temperature gas turbine. To assess the impact of selected parameters was made analysis by method of small-deflection. The advantages of one-circuit combined-cycle in comparison with more complex schemes. According to the research results, have been made corresponding conclusions.
\end{abstract}

\section{Introduction}

Combined Cycle Gas Turbines (CCGT) that allow significant increase of efficiency and biological safety $[1,2]$ of thermal power engineering have been actively used in world's power engineering in recent years. Binary CCGTs of utilization type on the basis of modern high-temperature gas turbines (GT) proved to be the most efficient [3, 4]. These CCGTs surpass power units in terms of thermodynamic efficiency and ecological factors. The endeavors the increase CCGT efficiency call for the development of units on cogeneration steam cycle with back-pressure steam turbine (CCGT DH) applied [5, 6]. These units are the object of the given research.

\section{Thermal efficiency of CCGT DH}

In CCGT DH, utilization of heat of exhaust GT gasses in heat recovery steam generator (HRSG) is done on two segments of heating cycle, i.e. with the resulting overheated steam and with heating reverse DH system water in tail surface of HRSG. The heat of exhaust steam is utilized with its transition to the consumer of technological steam or district heating system water fed to the direct network.

The CCGT DH diagram is rather simple as there is no need to use several levels of steam pressure and steam reheating. Fig. 1 shows the diagram of CCGT-DH with district heater $(\mathrm{DH})$ providing the customers with heat and hot water.

The increase of HRSG efficiency and the unit as a whole is realized through deep utilization of heat via decrease of temperature of exhaust gasses while transmitting heat to the reverse DH system water in gas-water district heater (GWDH). Temperature mode of

* Corresponding author: anton@,tpu.ru 
the heating system is a key one for the characteristics of CCGT DH steam section as the temperature of DH system water defines the pressure of exhaust steam at the exhaust of gas turbine

Thermal efficiency of CCGT DH can be assessed with so-called total efficiency of CCGT indicating the share of heat of fuel beneficially used in the unit. Beneficially used heat encompasses electric power of CCGT $N_{\mathrm{E}}$ and thermal power transmitted to heat consumers $Q_{H C}$.

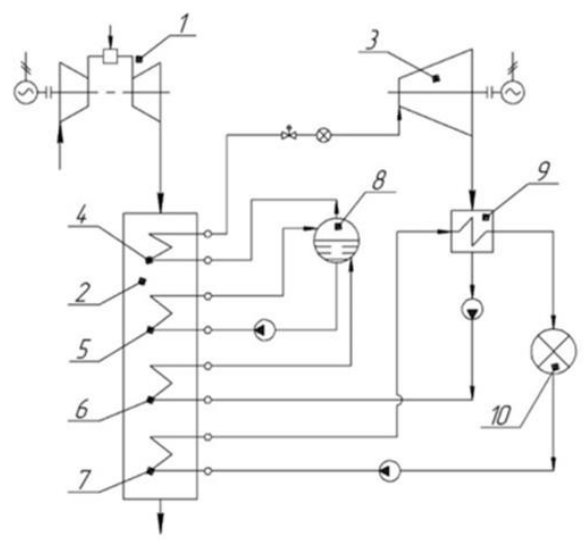

Fig. 1. The diagram of CCGT-DH with back-pressure steam turbine: 1 - gas turbine; 2 - heat recovery steam generator; 3 - steam turbine; 4 - superheater; 5 - evaporator; 6 - economizer; 7 GWDH; 8 -drum; 9 - DH; 10 - heat consumer.

The total efficiency of CCGT:

$$
\eta_{C C G T}=\frac{N_{E}+Q_{H C}}{Q_{C C}}=\frac{N_{E}^{G T}+N_{E}^{S T}+Q_{H C}}{Q_{C C}}=\frac{N_{E}^{G T}}{Q_{C C}}+\frac{N_{E}^{G T}+Q_{H C}}{Q_{C C}} .
$$

in which $Q_{C C}$ is heat fed from fuel to working fluid in the combustion chamber of gas turbine; $N_{E}^{G T}, N_{E}^{S T}$ - are electric powers of gas and steam turbines.

The energy balance of GT suggests: $Q_{C C}=N_{E}^{G T}+Q_{H R S G}^{H}+\Delta Q_{E G}$, in which $\Delta Q_{E G}$ is loss of heat with exhaust gasses from the heat recovery steam generator; $Q_{H R S G}^{H}$ is useful output of heat recovery steam generator. Loss of heat with outgoing gasses $\Delta Q_{E G}$ can be defined using the equation for efficiency of heat recovery steam generator:

$$
\eta_{H R S G}=\frac{Q_{H R S G}^{H}}{Q_{C C}-N_{E}^{G T}}=\frac{Q_{C C}-N_{E}^{G T}-\Delta Q_{E G}}{Q_{C C}-N_{E}^{G T}}
$$

in which denominator stands for heat of exhaust gasses of GT, from which they are fed to HRSG. Useful output of heat recovery steam generator equals:

$$
Q_{H R S G}^{H}=Q_{C C}-N_{E}^{G T}-\left(1-\eta_{H R S G}\right)\left(Q_{C C}-N_{E}^{G T}\right)=\left(Q_{C C}-N_{E}^{G T}\right) \cdot \eta_{H R S G} \cdot
$$

On the other hand, useful output of heat recovery steam generator is consumed for two components: electric power of steam section of CCGT $N_{E}^{S T}$ and thermal power fed to the heat consumer $Q_{H C}$. Hence, obtain the total efficiency: 


$$
\eta_{C C G T}=\frac{N_{E}^{G T}}{Q_{C C}}+\frac{N_{E}^{S T}+Q_{H C}}{Q_{C C}}=\eta_{G T}+\frac{Q_{C C} \cdot\left(1-\eta_{G T}\right) \cdot \eta_{H R S G}}{Q_{C C}}=\eta_{G T}+\left(1-\eta_{G T}\right) \cdot \eta_{H R S G} .
$$

This formula lacks efficiency of steam section of CCGT (SC) or any other factor characterizing its economy, i.e. thermal efficiency of CCGT DH does not depend on SC economy; it functions with no losses in the cycle: condensation heat of exhaust water steam is completely used for covering the load of heat consumers.

\section{The analysis of efficiency via method of small-deflection}

Method of small-deflection [7,8] allows obtaining the solution in general and numerical type by using the results of calculations of a certain basic variant. The method is based on equations linearization. As a result, the initial analytical equation is replaced with the equation with small-deflection of the arguments comprised. The obtained evident analytical dependence binds the changes of initial variables with the changes of function, which enables to analyze the changes of function with the help of coefficients of variable values effect.

Following the method of small-deflection, differentiate the equation of efficiency of CCGT DH (4):

$$
d \eta_{C C G T}=\frac{\partial \eta_{C C G T}}{\partial \eta_{G T}} d \eta_{G T}+\frac{\partial \eta_{C C G T}}{\partial \eta_{H R S G}} d \eta_{H R S G}
$$

Here, partial derivatives are: $\frac{\partial \eta_{C C G T}}{\partial \eta_{G T}}=1-\eta_{H R S G} ; \frac{\partial \eta_{C C G T}}{\partial \eta_{H R S G}}=1-\eta_{G T}$. Substituting partial derivations in (5), we obtain: $d \eta_{C C G T}=\left(1-\eta_{H R S G}\right) d \eta_{G T}+\left(1-\eta_{G T}\right) d \eta_{H R S G}$. Let's first consider finite increment and then relative deviations:

$$
\frac{\Delta \eta_{C C G T}}{\eta_{C C G T}}=\frac{1}{\eta_{C C G T}}\left[\left(1-\eta_{H R S G}\right) \eta_{G T} \frac{\Delta \eta_{G T}}{\eta_{G T}}+\left(1-\eta_{G T}\right) \eta_{H R S G} \frac{\Delta \eta_{H R S G}}{\eta_{H R S G}}\right] .
$$

Considering the indication of coefficient at variable, we obtain:

$$
\delta \eta_{C C G T}=K_{1} \delta \eta_{G T}+K_{2} \delta \eta_{H R S G}
$$

Here, coefficients of effect $K_{l}$ and $K_{2}$ are defined through values of "basic" variant, having index " 0 " in the formulae:

$$
K_{1}=\frac{\left(1-\eta_{H R S G 0}\right) \eta_{G T 0}}{\eta_{C C G T 0}} ; K_{2}=\frac{\left(1-\eta_{G T 0}\right) \eta_{G T 0}}{\eta_{C C G T 0}} .
$$

CCGT DH, shown in figure 1, takes Siemens SGT5-4000F gas turbine as a basis. In nominal conditions at ambient temperature of minus $40{ }^{\circ} \mathrm{C}$, taken as a basic variant, gas turbine has the following characteristics: electric efficiency $-35.37 \%$; electric capacity 247.6 MW; heat fed to the combustion chamber with fuel - 700.1 MW; exhaust gas temperature $-594.8^{\circ} \mathrm{C}$; exhaust gas flow $-644.9 \mathrm{~kg} / \mathrm{s}$.

For the steam section of CCGT, values of indices in basic variant are determined by the balance sheet [8] and given in table 1 . For the given values of variables of basic variant of CCGT DH, coefficients are as follows: $K_{I}=0.0687, K_{2}=0.6050$. 
Table 1. Basic values of steam section of CCGT DH and efficiency of the unit in basic variant.

\begin{tabular}{|l|c|}
\hline \multicolumn{1}{|c|}{ Parameter, dimension } & Value \\
\hline Initial pressure of the steam, $\mathrm{MPa}$ & 5.0 \\
Initial temperature of the steam, ${ }^{\circ} \mathrm{C}$ & 540 \\
Electric capacity, MW & 68.51 \\
Thermal power, MW & 302,9 \\
Temperature of the direct heating water, ${ }^{\circ} \mathrm{C}$ & 110 \\
Efficiency of HRSG & 0.828 \\
Total efficiency of CCGT & 0.885 \\
\hline
\end{tabular}

Taking into account the resulting values, we obtain dependency of efficiency of the analyzed CCGT DH on the factors in the form of equation in small-deflection:

$$
\delta \eta_{C C G T}=0.0687 \cdot \delta \eta_{G T}+0.6050 \cdot \delta \eta_{H R S G} .
$$

The analyses of the equation shows that efficiency of using heat of gas turbine exhaust gasses in heat recovery steam generator has a much stronger impact on the efficiency of using heat of fuel than efficiency of gas turbine. With $1 \%$ change of $\eta_{H R S G}$, efficiency of CCGT $\eta_{C C G T}$ changes on $0.6050 \%$. The increase of efficiency of gas turbine on $1 \%$ leads to the increase efficiency of CCGT on $0.0687 \%$. Temperature of exhaust gasses from HRSG has the defining value. In CCGT DH, this temperature definitely depends on the temperature of reverse DH system water.

\section{Conclusion}

According to the research results, we can draw the following conclusions.

1. A simple schemes of CCGT with back-pressure steam turbine provides high reliability of CCGT due to single circuit and lack of steam reheating.

2. Total efficiency of CCGT DH does not depend on economy of steam section, as SC functions with no losses in the cycle.

3. Thermal efficiency of CCGT DH is mostly affected by the completeness of using of heat of gas turbine exhaust gasses in heat recovery steam generator.

4. To increase the efficiency of heat recovery steam generator and CCGT DH as a whole, a decrease of temperature of exhaust gasses within sustainable limits is needed. This is defined by the valid choice of temperature mode of the heating system.

\section{References}

1. D.Gvozdyakov, V.Gubin, Chem. and Pet. Eng. 51, 201 (2015)

2. A.V. Vorobiev, E.M. Dutova, A.S. Latyshev, MATEC Web of Conf. 72, 01125 (2016)

3. G. Olkhovsky, V. Trushechkin, Therm. Power Plants 1, 2 (2013)

4. A. Uvarov, A. Antonova, A. Vorobjev, MATEC Web of Conf. 37, 01062 (2015)

5. A. Gushchin, Turbiny i dizeli 7, 16 (2007) [in Russia]

6. A. Trukhniy, Parogazovyye ustanovki elektrostantsiy (MEI, Moskow, 2013) [in Russia]

7. G. Olkhovsky, Power gas turbine plants (Energoatomizdat, Moskow, 1985) [in Russia]

8. A.M. Antonova, A.V. Vorobiev, A.S. Orlov, MATEC Web of Conf. 23, 01069 (2015)

9. K. Savina, A. Abramovskih, V. Haymin, S. Lavrinenko, MATEC Web of Conf. 72, 01042 (2016) 